\title{
Naltrexone, a therapeutic alternative in Darier disease
}

\author{
Dennise L. Smith-Pellegrin ${ }^{1}$, María R. Rivera-Vega ${ }^{1}$, Jorge R. Cazarín-Barrientos², Aralí Melgarejo-Gómez², \\ Olga M. Messina-Baas ${ }^{3}$, and Sergio Cuevas-Covarrubias ${ }^{1 *}$ \\ ${ }^{1}$ Department of Genetics; ${ }^{2}$ Department of Dermatology; ${ }^{3}$ Department of Ophthalmology. General Hospital of Mexico, Mexico City, Mexico
}

\begin{abstract}
Darier disease is a clinically variable rare disease with autosomal dominant inheritance caused by mutations in ATP2A2 gene. It affects skin, mucous membranes, and nails. The onset of symptoms is during adolescence and persists through adulthood, affecting quality of life. It presents papules and small malodorous keratotic yellow to brown plaques that emerge predominantly in seborrheic areas. In the present study, we describe a patient with Darier disease successfully treated with naltrexone at low doses.
\end{abstract}

Key words: Darier disease. Naltrexone. Darier disease treatment. ATP2A2.

\section{Introduction}

Darier disease or Darier-White disease (MIM 124200), also known as follicular keratosis, is a rare disease with autosomal dominant inheritance that affects skin, mucous membranes, and nails $\mathbf{s}^{1,2}$. It was first reported by Darier and White in 1889. The prevalence is estimated between $1 / 30,000$ and $100,000^{2-4}$. Onset of symptoms is in adolescence and persists during adulthood, affecting the quality of life. It presents papules and small malodorous keratotic yellow to brown plaques that emerge predominantly in seborrheic areas. Darier disease also may present palmoplantar pits, whitish papules in oral mucosa, and nail abnormalities. Occasionally, Darier disease can be accompanied by intellectual disability, epilepsy, and bipolar disorder ${ }^{1-3}$. The phenotype of the disease has clinical variability; two familial members affected by the same genetic defect could present different phenotype. Histopathological, Darier disease is characterized by dyskeratosis, round bodies and grains, and suprabasal acantholysis with clefts ${ }^{3}$.
The causative gene, ATP2A2, is located on chromosome 12q23-24.1 and codes for a sarco/endoplasmic reticulum type 2 ATPase (SERCA2), a calcium pump distributed throughout the endoplasmic reticulum². Molecular defects of ATP2A2 gene cause abnormalities in the system of calcium signals and consequently apoptosis and loss of adhesion between the suprabasal cells ${ }^{1}$.

Hailey-Hailey disease is a differential diagnosis, an entity in which the responsible gene ATP2C1, which codes for SPCA1, a calcium pump located in the Golgi apparatus. This disease commonly begins in adolescence with aggregation of erythema and small blisters in intertriginous areas that might be confused with Darier disease ${ }^{2}$.

At present, there is no curative treatment, most of the cases receive symptomatic treatment. Emollients and retinoids have been used, although retinoids have side effects (dry mucous membranes, epistaxis, itching, and sensitivity to light), therefore, they cannot be given for

\section{Correspondence:}

*Sergio Cuevas-Covarrubias

E-mail: sergiocuevasunam@gmail.com 0185-1063/C 2021 Sociedad Médica del Hospital General de Mexico. Published by Permanyer. This is an open access article under the CC BY-NC-ND license (http://creativecommons.org/licenses/by-nc-nd/4.0/).

Date of reception: 04-06-2021

Date of acceptance: 26-08-2021 DOI: $10.24875 / H G M X .21000039$
Available online: 18-10-2021 Rev Med Hosp Gen Mex. 2021;84(4):177-180 www.hospitalgeneral.mx 
a long time or management must be intermittent, in addition to the risk of relapse when treatment is interrupted as well as the teratogenic risk. Systemic retinoids are preferred when the disease is severe, or the patient does not respond to topical treatment ${ }^{1}$.

Another drug that has reported efficacy is cyclosporine; however, cyclosporine downregulates SERCA2 expression, hence, its mechanism of action is still unclear'.

Surgery can be helpful when there are localized painful lesions in flexion areas. Other alternatives that provide long-term remissions include excision, grafts, dermabrasion, and laser (CO2, erbium YAG), however, they are considered impractical therapies and more experience is still needed ${ }^{1}$.

Naltrexone is a well-tolerated drug which has been reported to participate in inflammation, immune responses, and at low doses, it has been shown to improve the clinical manifestations of patients with Hailey-Hailey disease, which, like Darier disease, is a genodermatosis due to alteration in intracellular calcium pumps 5 . In the present study, we describe a patient with Darier disease successfully treated with naltrexone at low doses.

\section{Case report}

A 30-year-old female patient was referred to the dermatology department for papules on the face and neck of long evolution as well as intense itching. She had received treatments that included four intramuscular injections of dexamethasone, fluocinolone, neomycin, and topical ointment of betamethasone, gentamicin, and clotrimazole without improvement. Physical examination showed papules, pustules, blackheads, seborrhea, and meliceric crusts on the face and neck; there were verrucous lesions on the back of the hands. The patient was diagnosed as acneiform reaction and flat warts. Laboratory studies were within normal parameters. She was initially treated with azithromycin $500 \mathrm{mg}$ every $24 \mathrm{~h}$ for 3 days and hydroxyzine $10 \mathrm{mg}$ twice, daily. Fifteen days later, she reported a slight improvement and started topical tretinoin at $0.05 \%$, loratadine $10 \mathrm{mg}$, and hydroxyzine $10 \mathrm{mg}$ at night. Two months later, the patient presented to the hospital due to retinoid intolerance, then, a Darier disease was suspected, and a biopsy was requested. Biopsy reported: epidermis showed slight irregular acanthosis with fusion of the interpapillary processes, foci of hypergranulosis, and hyperpigmentation of the basal layer. In the follicular epithelium, an intraepithelial cleft was observed

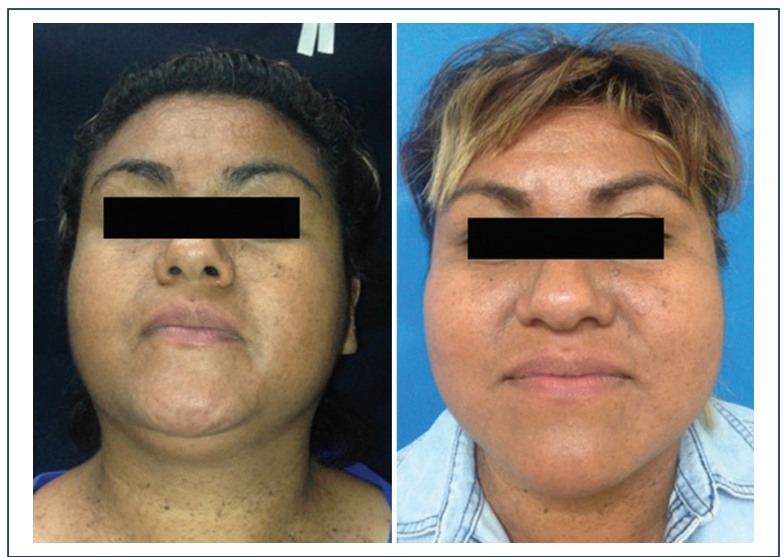

Figure 1. Patient before and after treatment with naltrexone.

with a single row of basaloid keratinocytes in its lower part; its interior presented dyskeratotic keratinocytes with eosinophilic cytoplasm and acantholytic keratinocytes, as well as some round bodies. Upper dermis showed perivascular inflammatory infiltrate of lymphocytes and some histiocytes. Therefore, the result was consistent with the diagnosis of Darier disease. The patient began with naltrexone a dose of $1.5 \mathrm{mg}$ every $24 \mathrm{~h}$ for 15 days, increasing the dose to $2 \mathrm{mg}$ every $24 \mathrm{~h}$ for 15 days, then $4 \mathrm{mg}$ daily for a month, and finally $12.5 \mathrm{mg}$ every $24 \mathrm{~h}$ for 3 months. The patient referred global improvement of 8 on a scale from 1 to 10 . On physical examination, the patient showed an improvement of the face, neck, and folds lesions, as well as termination of the pruritus (Fig. 1). However, the patient did not notice improvement in the scalp or in the papules of the hands. Secondary effects for the naltrexone therapy were not present. Naltrexone was indicated $12.5 \mathrm{mg}$ every $48 \mathrm{~h}$ but after 3 months the patient had a relapse, and the dose of $12.5 \mathrm{mg}$ every $24 \mathrm{~h}$ was reestablished with a good response. The patient gave her informed consent.

\section{Discussion}

To date, Darier disease has no cure, most of the cases receive symptomatic treatment in which lifestyle is important to avoid exacerbating factors such as high temperature and humidity, UV rays, and mechanical irritation. Oral lesions are asymptomatic, and treatment is not necessary ${ }^{1}$.

For skin lesions, emollients and retinoids such as tretinoin, isotretinoin, adapalene, and tazarotene have been used, although retinoids have side effects such 
as dry mucous membranes, epistaxis, itching, and sensitivity to light; therefore, they cannot be given for a long time or management must be intermittent, besides to the risk of relapse when treatment is interrupted as well as the teratogenic risk. Among the benefits, it has been found that retinoids are more effective than corticosteroids in monotherapy. In addition, topical retinoids can reduce hyperkeratosis in 3 months, although irritation is a common side effect. For this reason, some authors propose that an emollient combined with a medium strength steroid seems to be more appropriate ${ }^{1}$.

Systemic retinoids are preferred when the disease is severe, or the patient does not respond to topical treatment ${ }^{1}$. These drugs are aimed to reduce hyperkeratosis and are effective in $90 \%$ of the patients. Compared with acitretin, alitretinoin has fewer adverse effects and can be used intermittently during the summer when the disease is clinically more aggressive ${ }^{6}$.

Another drug that has reported efficacy is cyclosporine; however, cyclosporine downregulates SERCA2 expression, hence, its mechanism of action is still unclear ${ }^{1}$. Excision followed by split-thickness grafting, dermabrasion, or laser removal $\left(\mathrm{CO}_{2}\right.$ or erbium: $\left.\mathrm{YAG}\right)$ may yield a long-term remission. Destructive treatment must include the follicular infundibulum to prevent recurrences. Experience is necessary to avoid scarring, particularly in body areas at risk for hypertrophic scar or keloid formation ${ }^{1,7}$.

Light and laser devices have been emerging as promising therapeutic options for a disfiguring disease that still lacks, until today, an effective long-term treatment. Some authors have reviewed the clinical outcomes of different dermatologic lasers for the treatment of Darier disease. Pulse dye laser and $\mathrm{CO}_{2}$ lasers, particularly fractionated $\mathrm{CO}_{2}$ lasers, are the most used technologies so far and have demonstrated fast, long-lasting clinical and symptomatic improvements in Darier patients. Ablative lasers, including both $\mathrm{CO}_{2}$ and erbium: YAG, appear to be safe and effective in despite the slightly higher side effect profile (immediate post-operative erythema, pain, hyperpigmentation, and scarring). With the addition of the fractional capability to the $\mathrm{CO}_{2}$ laser, the intensity of the ablative lasers is now better tolerated. It should be noted that the extent of the total body surface area treated in patients should be carefully monitored, as a risk of a Darier disease flare has been noted with an increasing area of treatment. An optimal approach combining different treatments tailored to the patient's needs is warranted. Limitations of laser therapy are its high cost, its limited number of patient reports, and lack of standardized long-term follow-up. Although more robust and controlled studies using lasers are needed, it appears to be an alternative therapy in Darier disease for some authors ${ }^{8,9}$.

Naltrexone is an antagonist of opioid receptor and increases the activity of endorphins and dopamine. Naltrexone blocks the toll-like receptor 4 which stimulates pro-inflammatory pathways by activating IL-6, TNF alpha, and nitric oxide ${ }^{10}$. Naltrexone inhibits cell proliferation of $T$ and $B$ lymphocytes through the axis of the opioid growth factor-opioid growth factor receptor. In multiple sclerosis, Crohn's disease, and fibromyalgia, naltrexone has shown efficacy ${ }^{11,12}$.

Darier disease and Hailey-Hailey's disease (MIM 169600), both disorders of cornification, are due to defects in genes that code for intracellular calcium pumps in the keratinocyte. In Hailey-Hailey disease, naltrexone increases the intracellular calcium levels of keratinocytes, stimulating their proliferation and cell adhesion which helps wound healing ${ }^{5,11,12}$. Previous reports show good results in Hailey-Hailey disease with naltrexone at low doses of $4.5 \mathrm{mg} / \mathrm{day}$ or at doses of 12.5 and $50 \mathrm{mg}^{5,10,13,14}$.

Naltrexone, at low doses, has efficacy in Hailey-Hailey disease, pruritus, and other inflammatory and acantholytic diseases with no response to other treatments ${ }^{15}$. Due to the similarity between Darier and Hailey-Hailey disease, naltrexone would appear to be a good medication of choice for Darier. In our patient, clinical data improved with low doses of naltrexone, especially in the skin areas, where Hailey-Hailey disease has clinical manifestations, including the pruritus. A previous report showed variable results depending on the severity of the clinical manifestations using $5 \mathrm{mg}$ of naltrexone daily or combined with retinoids ${ }^{16}$. We found a good response with $12.5 \mathrm{mg}$ of naltrexone every $24 \mathrm{~h}$. In addition to the significant improvement in the patient, naltrexone was well tolerated, unlike retinoids, which were part of her previous pharmacological management in which the patient had shown only a slight response to treatment at the expense of retinoid intolerance.

\section{Conclusions}

Naltrexone is a safe drug that can be used in patients with Darier disease. Naltrexone showed a global improvement of $80 \%$ without side effects in a patient who had not presented improvement despite having received treatment for months with multiple 
therapies including antihistamines, antibiotics, and systemic and topical steroids, in addition to retinoids, which had been the only treatment that had shown at least a little improvement but at the cost of intolerance to them.

\section{Acknowledgments}

We'd like to thank the patient who participated in the study and Dr. Ricardo Alexander Diaz Rodríguez for his support.

\section{Funding}

The authors received no specific funding for this work.

\section{Conflicts of interest}

The authors declare that there are no conflicts of interest.

\section{Ethical disclosures}

Protection of human and animal subjects. The authors declare that the procedures followed were in accordance with the regulations of the relevant clinical research ethics committee and with those of the Code of Ethics of the World Medical Association (Declaration of Helsinki).

Confidentiality of data. The authors declare that they have followed the protocols of their work center on the publication of patient data.
Right to privacy and informed consent. The authors have obtained the written informed consent of the patients or subjects mentioned in the article. The corresponding author is in possession of this document.

\section{References}

1. Engin B, Kutlubay Z, Erkan E, Tüzün Y. Darier disease: A fold (intertriginous) dermatosis. Clin Dermatol. 2015;33:448-51.

2. Takagi A, Kamijo M, Ikeda S. Darier disease, J Dermatol. 2016;43:275-9.

3. Leong IU, Stuckey A, Ahanian T, Cederlo M, Wikstrom JD. Novel mutations in Darier disease and association to self-reported disease severity. PLoS One. 2017;12:e0186356.

4. Nellen RG, Steiilen PM, van Steensel MA, Vreeburg M, Frank J, van Geel M. Mendelian disorders of cornification caused by defects in intracellular calcium pumps: mutation update and database for variants in ATP2A2 and ATP2C1 associated with darier disease and Hailey-Hailey disease. Hum Mutat. 2017;38:343-56.

5. Campbell V, McGrath C, Corry A. Low-dose naltrexone: a novel treatment for Hailey-Hailey disease. Br J Dermatol. 2018;178:1196-8.

6. Letule V, Herzinger T, Ruzicka T, Molin S. Treatment of Darier disease with oral alitretinoin. Clin Exp Dermatol. 2013;38:523-5.

7. Hohl D, Mauro T. Darier disease and Hailey-Hailey disease. In: Bolognia JL, Jorizzo JL, Schaffer JV, editors. Dermatology. $3^{\text {rd }}$ ed. Philadelphia, PA: Mosby Elsevier; 2012. p. 887-97.

8. Kechichian E, Jabbour S, El Hachem L, Tomb R, Helou J. Light and laser treatments for keratosis pilaris: A systematic review. Dermatol Surg. 2020;46:1397-402.

9. O'Brien KF, Fricke MA, Kent RA, DeKlotz CM. Laser treatment of darier disease: report of two cases and systematic review of the literature. J Lasers Med Sci. 2020;11:395-404.

10. Albers LN, Arbiser JL, Feldman RJ. Treatment of Hailey-Hailey disease with low-dose naltrexone. JAMA Dermatol. 2017;153:1018-20.

11. Patten DK, Schultz BG, Berlau DJ. The safety and efficacy of low-dose naltrexone in the management of chronic pain and inflammation in multiple sclerosis, Fibromyalgia, Crohn's disease, and other chronic pain disorders. Pharmacotherapy. 2018;38:382-9.

12. Li Z, You Y, Griffind N, Fenga J, Shan F. Low-dose naltrexone (LDN): a promising treatment in immune-related diseases and cancer therapy. Int Immunopharmacol. 2018;61:178-84.

13. Ibrahim $\mathrm{O}$, Hogan SR, Vij A, Fernandez AP. Low-dose naltrexone treatment of familial benign pemphigus (Hailey-Hailey disease). JAMA Dermatol. 2017;153:1015-7.

14. Cao S, Lilly E, Chen ST. Variable response to naltrexone in patients with Hailey-Hailey disease. JAMA Dermatol. 2018;154:362-3.

15. Lee B, Elston D. The uses of naltrexone in dermatological conditions. J Am Acad Dermatol. 2018;18:33104-9.

16. Boehmer D, Eyerich K, Darsow U, Biedermann T, Zink A. Variable response to low-dose naltrexone in patients with Darier disease: a case series. J Eur Acad Dermatol Venereol. 2019;33:950-3. 